\title{
À "Frente" da Semana de Arte Moderna: a presença de Graça Aranha e Paulo Prado
}

\author{
"Ahead" the Week of the Modern Art: \\ the presence of Graça Aranha e Paulo Prado
}

Thais Waldman

Apesar de existir uma ampla e variada fortuna crítica sobre o modernismo em São Paulo - revistas, autores, grupos etc. -, que procura dar conta da pluralidade do legado modernista -, alguns nomes parecem relativamente esquecidos pelas historiografias do movimento entre nós. Isso tem levado à concentração das análises em certo número de autores, projetos e obras, eleitos como representantes emblemáticos do período. José Pereira da Graça Aranha (1868-1931) e Paulo da Silva Prado (1869-1943) são dois desses nomes esqueci-

O presente artigo é fruto de uma reflexão já apresentada em minha dissertação de mestrado Moderno bandeirante: Paulo Prado entre espaços e tradições, 2009, financiada pela FAPESP. Agradeço a orientação da profa. dra. Fernanda Arêas Peixoto e as sugestões de Enrico Spaggiari.

Thaïs Waldman é mestre em Antropologia Social pela Universidade de São Paulo (tatawald@yahoo.com.br). Artigo recebido em 30 de dezembro de 2009 e aprovado para publicação em 5 de março de 2010. 
dos. Reconhecidos como personagens centrais pelo grupo de intelectuais e artistas ligados à Semana de Arte Moderna de 1922, são, contudo, com raras exceções, ${ }^{1}$ deixados de lado pelos estudiosos em geral e, em geral, só estão presentes nas análises de bastidores e/ou em referências de terceiros.

Ao ocuparem uma posição fora do "centro", Paulo Prado e Graça Aranha fornecem um acesso privilegiado a uma cena ambígua, complicada e repleta de fios soltos, aos quais eles mesmos se encontram emaranhados. Este artigo pretende observar mais atentamente suas redes de sociabilidade e inserção, que revelam, entre outras coisas, as ambivalências do engate de ambos os autores em um projeto "moderno", assim como certas ambivalências presentes no interior do próprio movimento modernista brasileiro.

\section{Graça Aranha: o "protomártir da nova era"}

A importância de Graça Aranha para o movimento modernista de 1922 tem sido muitas vezes minimizada, apesar da repercussão de suas obras e de ter sido seu o discurso de abertura da Semana de Arte Moderna. Definido por Oswald de Andrade, em fevereiro de 1922, como o "protomártir da nova era" (apud Boaventura, 2000: 108), descrito por Mário de Andrade, na mesma época, como "a antemão da Semana" (Ibidem: 61), Graça Aranha, aos poucos, passa a ter sua presença sistematicamente desprezada nas avaliações do movimento. Ao que parece, isso se deve à incorporação de um discurso formulado pelos próprios participantes do movimento, que, no decorrer do tempo, elegem e cristalizam as imagens de Mário de Andrade (1893-1945) e Oswald de Andrade (1890-1954) como seus líderes legítimos, o que acaba por ofuscar a pluralidade do grupo modernista. $^{2}$

Além de diplomata, Graça Aranha fora um os fundadores da Academia Brasileira de Letras e se consagrara nacionalmente com a publicação do romance Canaã (1902). Nas palavras de Di Cavalcanti, era "um nome sonoro de antologia escolar" (Di Cavalcanti, 1955: 112). Mário de Andrade, em artigo publicado por ocasião da Semana, explica que Graça Aranha emprestou para um projeto até então "inválido" o prestígio de seu renome e o apoio de sua atividade (apud Boaventura, 2000: 61). Desse modo, completa Di Cavalcanti, ele teria dado um ar de "seriedade" ao evento, pois "sua habilidade de diplomata, seu savoir faire de mundano, sua autoridade de mais velho, agiam como música sedutora" (Di Cavalcanti, 1955: 114).

Secretário de Joaquim Nabuco (1849-1910), Graça Aranha havia passado um longo período na Europa, com estadas intermitentes no Brasil. Esteve em Paris, Londres e Roma, entre 1899 e 1903, época na qual frequentava o aparta- 
mento parisiense de Eduardo Prado (1860-1901), por meio de quem conhece Paulo Prado, seu sobrinho. De volta ao Brasil, entre 1904 a 1911, inicia um romance com Nazareth Prado (1875-1949), irmã de Paulo, mas logo retorna à Europa como diplomata, regressando definitivamente ao Brasil somente em 1921, meses antes da concretização da Semana. Seu retorno definitivo ao país e, mais especificamente, sua longa estada em São Paulo, quando sua esposa o esperava no Rio de Janeiro, estavam diretamente relacionados não apenas a um desejo de renovação estética e/ou a vontade de reencontrar Nazareth: Aranha tinha também importantes negócios comerciais a serem resolvidos na capital paulista.

Desde o início do século XX, Graça Aranha vinha estreitando relações com a família Prado, sobretudo com Antônio Prado (1840-1929) e seus filhos, Paulo e Nazareth. Este mesmo círculo - junto a Oduvaldo Pacheco e Silva, marido de Nazareth, e Afonso Arinos de Melo Franco (1868-1916), também casado com uma irmã de Paulo Prado - havia organizado, em 1915, a vinda de Graça Aranha a São Paulo, para uma conferência oficialmente promovida pela Sociedade de Cultura Artística da cidade. Durante a conferência, realizada no recém-inaugurado Teatro Municipal - cuja construção, autorizada pelo governo de Antônio Prado, em 1903, fora concluída em 1911 -, Graça Aranha discursou sobre "A mocidade heroica de Joaquim Nabuco", tema provavelmente escolhido por ele mesmo.

Por ocasião da conferência, Graça Aranha já estava envolvido com os negócios da família Prado, que não eram poucos. Dois meses antes, em fevereiro de 1915, Antônio Prado - que, na época, presidia um grande número de empresas, como o Banco do Comércio e da Indústria, a Companhia Paulista de Estradas de Ferro, o Curtume Água Branca, o Frigorífico Barretos, a Vidraria Santa Marina, além de negócios imobiliários no Guarujá e o Automóvel Clube - lhe havia enviado uma carta a respeito de uma remessa de café para a Rússia, via Estocolmo, e sobre as exportações de carnes congeladas que a família começara a fazer para a Itália e Inglaterra (apud Azevedo, 2002). ${ }^{3}$ Graça Aranha lhe responde oferecendo sua ajuda para intermediar os negócios da família Prado na Europa (Ibidem). ${ }^{4}$

Nesse período, a Companhia Prado Chaves - primeira exportadora brasileira de café, fundada em 1887 e então sob direção de Paulo Prado -, 5 já era a maior exportadora de café da Primeira República, mas no setor de carnes congeladas a situação era bem diferente e o auxílio de Graça Aranha era de grande valia. Tratava-se de um novo ramo, com um mercado tradicional já ocupado, sobretudo pelos argentinos, mas com novos e gigantescos mercados abrindo-se rapidamente, envolvendo grande concorrência. Assim, para investir na venda de carnes congeladas, a família Prado fundara, em 1913, a Companhia Frigorífica e Pastoril de Barretos. 
Antigo funcionário da Companhia Prado Chaves, Pedro Luiz Pereira de Sousa explica que foi Paulo Prado quem trouxe o know-how e os materiais da Europa e a mão de obra especializada da Argentina e dos Estados Unidos. Além disso, Paulo Prado teria se associado à poderosa Companhia Mecânica e Importadora, do conde Alexandre Siciliano (1860-1923), que também contava com a família Prado entre os acionistas herdeiros (Sousa, 1950).

Aparentemente, pelo que se pode depreender das correspondências trocadas entre Antônio Prado e Graça Aranha, o autor de Canãa passa a intermediar, a partir de 1915, os interesses da Companhia Frigorífica e Pastoril de Barretos e os da Companhia Mecânica e Importadora de São Paulo junto ao governo inglês. Para isso, começa a receber mensalmente, de ambas as companhias, mil e quinhentos réis (Azevedo, 2002). Não por acaso, será descrito por Lima Barreto, em 1917, como o "caixeiro-viajante" dos Prados (apud Barbosa, 1952: 250).

Figura prestigiada e com bom trânsito no circuito político-intelectual que governava as nações capitaneadas pela França e pela Inglaterra, Graça Aranha há de ter visto, com a ajuda da família Prado, as possibilidades de ganho que a guerra abria a esse novo tipo de investimento. Para justificar suas ações, irá defender os negócios realizados junto à família Prado como parte de uma guerra econômica contra a Alemanha, pelo abastecimento das nações aliadas. Já em carta à esposa, a justificativa será outra: "já é tempo de ser formiga - e deixar o canto de cigarra - farei tudo para ganhar a nossa vida e nos libertar de tanta pobreza" (apud Azevedo, 2002: 206). ${ }^{6}$

Ao retornar definitivamente ao Brasil, em novembro de 1921, além de tratar dos empreendimentos da família Prado, Graça Aranha visita a primeira exposição de quadros e desenhos de Emiliano Di Cavalcanti (1897-1976), intitulada "Fantoches da meia-noite", na livraria O Livro, de Jacinto Silva. Anos depois, Di Cavalcanti explica como se deu tal visita:

O velho Jacinto Silva chamou-me misteriosamente a um canto e anunciou-me a presença de Graça Aranha em São Paulo, pedindo-me que eu fizesse o possível para reunir gente nova no recinto de minha exposição, porque o glorioso acadêmico desejava contatos com a mocidade literária e artística de São Paulo. (...) [mas] mal havia terminado de me pedir a convocação dos moços paulistas, eis que chega Graça Aranha (Di Cavalcanti, 1955: 112).

Ainda que, segundo Di Cavalcanti, Graça Aranha tenha observado suas obras com "gloriosa distância", criticando o "atormentado" de seus desenhos e quadros, é nessa exposição que ele inicia uma aproximação com os futuros parti- 
cipantes da Semana de 1922, sendo apresentado pessoalmente a Mário e Oswald de Andrade, Menotti del Picchia (1892-1988) e Guilherme de Almeida (1890-1969) ((Di Cavalcanti, 1955: 112-113). Ao se aproximar dos modernistas de São Paulo, Aranha logo pensa em Paulo Prado - com quem, aliás, já havia conversado sobre "os jovens muito modernos" que conhecera em São Paulo - e lhes sugere que o procurem, pois acreditava que ele seria simpático ao movimento, por achar positiva a "renovação" (apud Azevedo, 2002: 268). Di Cavalcanti esclarece um pouco mais essa relação:

Graça Aranha tinha uma ligação de amizade com Paulo Prado, personalidade que nenhum de nós conhecia e muito menos sabíamos ser um erudito da história do Brasil e um escritor excelente. Graça Aranha explicou quem era Paulo Prado e suas disposições em relação ao nosso movimento. Partindo para o Rio, Graça deu-me um cartão de apresentação a Prado e fui eu, do grupo modernista, o primeiro a conhecer aquela figura nobre e elegante de civilizado paulista, educado pelo tio Eduardo Prado, por Eça de Queirós, amigo de Claudel, homem que conheceu Oscar Wilde, dançarinas do tempo de Degas e o próprio Degas (Di Cavalcanti, 1955: 114-115).

Após a virada do ano, no entanto, Graça Aranha escreve a sua esposa e afirma ter encontrado entre os paulistas um clima de "desânimo", pois faltava apoio material à Semana (Azevedo, 2002: 271). ${ }^{7}$ Paulo Prado, potencial financiador do evento, parecia estar mais envolvido com os negócios e com a política do que com a literatura e as artes. Segundo as próprias palavras do próprio Prado, "outros cuidados fala[va]m mais alto do que as mais atraentes polêmicas artístico-literárias" (Prado, 1926). Mas "agora tudo sai!", afirma Aranha, “estou organizando um comitê, com Paulo Prado à frente" (Azevedo, 2002). Assim, "a muito custo (...) começaram os preparativos das festas...” (Di Cavalcanti, 1955: 114). Além de incentivar a atuação de Prado, Aranha foi também responsável por acertar algumas participações cariocas no programa do evento, como as de Ronald de Carvalho (1893-1935) e Heitor Villa-Lobos (1887-1959), com os quais mantinha laços de amizade (Azevedo, 2002).

Como reconhecimento de seu prestígio enquanto viabilizador da arte moderna, Graça Aranha é quem irá proferir a conferência inaugural da Semana de 1922, intitulada “A Emoção Estética na Arte Moderna”. Retomando aí as ideias centrais de seu livro recém-lançado, A estética da vida (1921), Aranha lança as bases do evento modernista: "o que hoje fixamos não é a renascença de uma arte que não existe. É o próprio comovente nascimento da arte no Brasil, e como não 
temos felizmente a pérfida sombra do passado para matar a germinação, tudo promete uma admirável florada artística" (Aranha, 1968: 744).

Deixando de lado o significado filosófico de sua concepção de arte (Jardim, 1978), podemos observar uma recusa em ver na imitação da natureza uma finalidade artística. Opondo-se a uma natureza "fixa” e "eterna”, Graça Aranha explica que "tudo passa" e que o artista moderno deve estar em "íntima correlação com a vida moderna na sua expressão mais real e desabusada" (Aranha, 1968: 742). Nesse sentido, suas formulações parecem se afinar ao projeto modernista de renovação, que ele, não por acaso, anuncia ritualmente com o pronunciamento de abertura.

Parece claro, portanto, que a centralidade de Graça Aranha na Semana de 1922 diz respeito não apenas ao prestígio e ao apoio que ele oferece ao grupo, mas também às suas ideias, que irão dialogar com as propostas modernistas em curso. Meses antes do evento, quando da elaboração de $A$ estética da vida, Aranha parece evidenciar também aquilo que será central no "segundo tempo modernista", ou seja, que sem a afirmação da nacionalidade a integração brasileira ao universal não estaria assegurada (Jardim, 1978). ${ }^{8}$ A "estética" por ele proposta reside justamente na integração do "eu" — a nacionalidade — à "realidade cósmica", e à sua "tradução estética" (Aranha, 1968: 734). Nesse sentido, não parece exagerado afirmar que o modernismo brasileiro é profundamente marcado por suas reflexões. ${ }^{9}$

Todavia, a literatura e as artes expandem-se em direção à política e vice-versa. Menos de 15 dias após a realização da Semana de Arte Moderna, as eleições presidenciais consagraram a vitória do candidato situacionista, Artur Bernardes (1875-1955), o que levou algumas unidades militares do Rio de Janeiro e do Mato Grosso a se insurgirem contra o governo. Entre elas estava a unidade do Forte de Copacabana, que iniciou sua revolta em 5 de julho, no mesmo dia em que Graça Aranha telegrafou a seguinte mensagem a Paulo Prado, em uma provável tentativa de articular a adesão paulista: "tumor arrebenta hoje" (apud Anjos, 1975: 152).

Muitos dos suspeitos de conspirar contra o governo são presos no dia seguinte ao levante de Copacabana, entre eles Graça Aranha, que ficará detido durante quase um mês. Nessa ocasião, Oswald de Andrade teria endereçado ao governo um manifesto de intelectuais paulistas, por ele redigido, pedindo a soltura do amigo. Logo após ser liberado, Aranha é convocado novamente para se apresentar à Polícia para uma acareação, mas prefere se afastar do Rio de Janeiro e da perseguição policial, fugindo para o interior de São Paulo, onde se estabelece em uma das fazendas de Antônio Prado, a São Martinho (Azevedo, 2002).

De acordo com as anotações do diário de Tristão de Athayde, Graça Aranha é mais uma vez detido em 1924. Embora não acredite no seu envolvimento 
com o movimento político paulista, Tristão ressalta que Aranha era sempre visto ao lado de Antônio Prado, "que seguramente anda[va] com o dedo em todas essas tramas revolucionárias" (Ibidem: 385). Inclusive, no "Manifesto Revolucionário de 1924", publicado em diversos jornais da época, os "chefes do movimento revolucionário" chegam a convidar publicamente Antônio Prado para assumir o governo de São Paulo (apud Silva, 1964: 531).

Talvez como uma forma de manifestar apoio ao escritor perseguido e à sua postura antigovernista, a redação da Klaxon - Mensário de Arte Moder$n a,{ }^{10}$ a primeira revista modernista do Brasil, resolve lançar o último número de 1922 inteiramente dedicado a Graça Aranha. Como a Klaxon não possuía diretor ou redator-chefe -funcionando como um órgão colegiado no qual todos participavam das diferentes etapas de sua realização, e Paulo Prado era integrante do grupo da revista -, é bem possível que tal ideia tenha surgido no círculo da família Prado. De qualquer maneira, a homenagem é acatada pela Klaxon, ainda que as colaborações mostrem ser o personagem um tanto controverso. Os ensaios publicados são de amigos do homenageado, como os cariocas Ronald de Carvalho e Renato de Almeida. Mário de Andrade, presença frequente nos números anteriores, aqui comparece só com um poema, assim como Guilherme de Almeida e Sérgio Milliet (1898-1966). De Tarsila do Amaral (1886-1973), é publicado um retrato de Graça Aranha. De Oswald, nem uma só palavra.

Dois anos depois, as controvérsias em torno de Graça Aranha aumentam. Ao proferir a conferência “O Espírito Moderno", na Academia Brasileira de Letras, em junho de 1924, Aranha não somente propõe seu famoso desafio à instituição - "se a Academia não se renova, morra a Academia" -, como ressalta que "o primitivismo dos intelectuais é um ato de vontade, como o arcadismo dos acadêmicos" (Aranha, 1968: 53-54). Oswald de Andrade, que havia publicado no início do mesmo ano seu "Manifesto da Poesia Pau-Brasil", não fica nada satisfeito com o comentário daquele que tinha sido por ele caracterizado, ao lado de Paulo Prado, como "à frente" do movimento modernista (apud Boaventura, 2000: 53). Poucos dias depois, Oswald publica no jornal $A$ Manhã um ataque direto ao conferencista:

Graça Aranha é um dos mais perigosos fenômenos de cultura que uma nação analfabeta pode desejar. Leu mais duas linhas do que os outros, apanhou três ideias além das de uso corrente e, faquirizado por uma hipnose interior, crédulo e ingênuo, quer impor à outrance os seus últimos conhecimentos, quase sempre confusos e caóticos" (apud Batista et al., 1972: 216). 
Ao longo de todo o artigo, Oswald de Andrade procura desmoralizar a figura de Graça Aranha. Revela, ainda, que o contato de Aranha com o cubismo, um dos temas da conferência na Academia, teria ocorrido "apenas há três semanas, tomando chá comigo e Paulo Prado no ateliê na pintora Tarsila do Amaral" (Ibidem: 217). Em carta ao poeta Manuel Bandeira, Mário de Andrade afirma que Graça Aranha teria confessado a Paulo Prado que aquela era mesmo uma crítica dirigida a Oswald e ao seu interesse pelas propostas primitivistas europeias, o que, para Mário, criou uma situação muito “desagradável” (apud Moraes, 2000: 135). ${ }^{11}$ Esses indícios sugerem que, de fato, não havia grupos definidos durante a Semana de Arte Moderna; as divergências e coletivos mais definidos parecem surgir posteriormente. ${ }^{12}$

O impacto positivo deixado por Graça Aranha em Oswald de Andrade, e em outros participantes da Semana, por ocasião da realização do evento, parece ter aos poucos se alterado, ao mesmo tempo em que os próprios modernistas redefiniam seus agrupamentos e disputavam a liderança do movimento. Mário de Andrade, por exemplo, ao enviar uma carta de solidariedade a Aranha pelo seu desligamento definitivo da Academia, confessa a Manuel Bandeira ter subtraído uma "ironia" na carta ao "camarada": "a ironia vinha do sacrifício que ele fazia da Academia para ganhar a grande Glória de ser condutor de gentes" (apud Moraes, 2000: 154). ${ }^{13}$ No ano seguinte, em carta a Paulo Prado, Mário conclui que Graça Aranha só deu seu apoio à Semana de 1922 por ser um "interesseiro", "interessado" e "interessista" (apud Calil, 2004: 224). ${ }^{14}$

As acusações de que Graça Aranha queria tomar para si a liderança do movimento atingem tais dimensões que a redação do jornal $A$ Noite, após publicar, em 1925, uma entrevista na qual Mário de Andrade o chama de "papa do futurismo", publica também uma nota ressaltando que "não é verdade que o escritor Graça Aranha tenha vindo a esta casa protestar por termos dado ao Sr. Mário de Andrade e não a ele o papado do futurismo" (apud Batista et al., 1972: 279). No mesmo ano, em artigo publicado na Estética, revista carioca modernista dirigida por Sérgio Buarque de Holanda (1902-1987) e Prudente de Morais Neto (1895-1961), Mário faz questão de enfatizar que o modernismo não veio ao Brasil "dentro da mala de Graça Aranha" (Andrade, M., 1925: 338).

Pelo que se sabe, Paulo Prado, apesar de ser o autor do prefácio da Poesia Pau Brasil (1925), de Oswald de Andrade, não se manifestou a respeito dessas acusações, mantendo-se diplomaticamente afastado de tais polêmicas. Graça Aranha não só continuará participando dos empreendimentos da família Prado, como irá romper de vez - embora não publicamente - seu casamento oficial para ficar com Nazareth (Azevedo, 2002). Inclusive, em 1928, Prado será um dos colaboradores da revista carioca Movimento Brasileiro, dirigida por Aranha e Ronald de Carvalho. Tal publicação, em seu primeiro número, adianta aos seus leitores 
trechos do ainda inédito Retrato do Brasil, de Paulo Prado, e elogia o autor do livro. ${ }^{15}$ Assim, em meio a tantas controvérsias, Prado parece ter preservado sua amizade com Graça Aranha.

\section{Paulo Prado: o "fautor" da Semana de 1922}

Ao lado de sua intensa atividade como editor, organizador, mecenas e fomentador da arte moderna, Paulo Prado é autor de dois livros sobre aspectos sociais e culturais do Brasil, a partir da experiência colonial, publicados em momento de maturidade: Paulística: história de São Paulo (1925) e Retrato do Brasil: ensaio sobre a tristeza brasileira (1928). Trata-se, esta última, de uma obra que, segundo Oswald de Andrade, revelou aos brasileiros a "existência" do Brasil (Andrade, O., 1929) ou, nas palavras de Mário de Andrade, "fez papel de salva-vidas" (apud Calil, 2004: 223);16 por outro lado, foi escrita em diálogo constante com o historiador Capistrano de Abreu (1853-1927), que Paulo Prado conhece por intermédio do tio, Eduardo Prado, e a quem ele chamará diversas vezes de "Mestre".

No entanto, ainda que Paulo Prado seja frequentemente mencionado em estudos sobre os anos 1920 e sobre o modernismo, figurando também em correspondências e notícias da época, pouco foi escrito sobre ele. Bisneto do barão de Iguape, Paulo Prado foi criado no seio de uma tradicional família paulista ligada, como já vimos, à produção do café. Após graduar-se na última turma do Império, estabeleceu-se logo em seguida em Paris, na casa do tio, o historiador monarquista Eduardo Prado. É no interior do círculo de amigos do tio - Graça Aranha, Joaquim Nabuco, Afonso Arinos, Eça de Queirós (1845-1900), Oliveira Martins (1845-1894), barão do Rio Branco (1845-1912), Domício da Gama (1862-1925), Olavo Bilac (1865-1918), entre outros - que Paulo Prado afirma ter “apura[do] o [seu] patriotismo" (Prado, 1922: 5).

Além de ser um dos principais produtores e exportadores de café da época e de ter publicado dois volumes de interpretação histórica sobre a formação da nação e do povo brasileiro, Paulo Prado adquiriu e (re)editou documentos inéditos sobre a história colonial brasileira. Trouxe para São Paulo as novidades das vanguardas artísticas europeias, financiou viagens de artistas e intelectuais modernistas, brasileiros e estrangeiros, publicou artigos sobre a situação política, financeira, cultural e artística do incipiente século XX em importantes periódicos paulistas e cariocas - como O Estado de S. Paulo, Correio da Manhã, Correio Paulistano, Fornal do Comércio, O Fornal e Revista do Brasil; participou da fundação e do controle de revistas modernistas - como a Klaxon, Terra Roxa e outras terras e a Revista Nova; e, por fim, marcou presença como um dos principais organizadores e financiadores da Semana de Arte Moderna. 
Alguns meses antes de iniciar sua correspondência com o historiador Capistrano de Abreu, Paulo Prado adquiriu um quadro na histórica exposição de Anita Malfatti (1889-1964), em 1917, travando, ao que parece, seu primeiro contato com os futuros participantes de Semana de Arte Moderna. Esse contato com os jovens brasileiros será aprofundado em Paris, o que não soa estranho. Afinal, os arredores da Place de Clichy, no início do século XX, haviam se transformado, nos termos de Paulo Prado, no "umbigo do mundo" (Prado, 1925: 5).

Na década de 1920, Paris e sua efervescência cultural atraíam artistas e mecenas de todos os lugares. No caso dos brasileiros, lá estavam Victor Brecheret (1894-1955), Tarsila do Amaral, Anita Malfatti, Emiliano Di Cavalcanti, Heitor Villa-Lobos, entre outros; muitos deles patrocinados por Paulo Prado, como Brecheret, Di Cavalcanti e Villa-Lobos. Paulo Prado aparece aqui, já em idade madura, como um importante mediador entre São Paulo e Paris.

O envolvimento de Paulo Prado, assim como o de Olívia Guedes Penteado (1872-1934), com a comercialização de café no exterior - já que ambos eram sócios de casas comissárias com filiais e frentes europeias - acabou por refinar-lhes o gosto pela arte moderna, tornando-os mais sensíveis às linguagens das vanguardas artísticas (Miceli, 2003). Essa inserção econômica particular, que impunha deslocamentos regulares para o exterior, abriu novos horizontes no plano da atividade cultural, o que permitiu que os dois trouxessem para o Brasil as novidades que encontravam na Europa. Viúva de Inácio Penteado, grande exportador de café e dono de agência comissária com filial no porto de Havre, Olívia frequentava, desde jovem, o meio parisiense. Segundo depoimento de Oswald de Andrade,

[Olívia] não foi, em absoluto, uma "snob"; tinha gosto. Uma influência decisiva sobre ela talvez fosse Paulo Prado, seu grande amigo. Ela se esclareceu quanto à arte moderna, em nossa companhia, em Paris - comigo, Paulo Prado, Sérgio Milliet, Tarsila, Di Cavalcanti, Villa-Lobos" (apud Dantas, 1975: 73). ${ }^{17}$

Mais do que "esclarecer" Olívia, Paulo Prado parecia querer estabelecer uma mediação entre as elites conservadoras do Brasil e a renovação estética parisiense. Assim, tornou-se o primeiro a trazer para o país uma tela cubista, um quadro de seu amigo Fernand Léger (1881-1955), que ironicamente será pendurado de cabeça paa baixo no salão de sua casa (Cendrars, 1957). Paulo Prado se havia aproximado de Léger provavelmente por intermédio de Tarsila do Amaral e Oswald de Andrade (Amaral, 2003). Ao lado de suas respectivas companheiras, 
Prado e Léger eram vistos com frequência em Paris, quase sempre acompanhados do poeta de vanguarda Blaise Cendrars (1887-1961), ${ }^{18}$ que Prado também conheceu por intermédio de Oswald (Calil, 2004).

Se Paulo Prado é um elo de mediação entre o Brasil e o exterior, ele não apenas patrocina a viagem de modernistas brasileiros a Europa, como também a de estrangeiros para o Brasil, como é o caso do poeta Blaise Cendrars e de um dos pioneiros da arquitetura moderna mundial, Le Corbusier (1887-1965), ${ }^{19}$ que Prado conhece por intermédio de Cendrars. O círculo modernista, portanto, amplia as relações de Paulo Prado, introduzindo-o a novos e importantes personagens.

Por volta de 1920, quando Paulo Prado começa a viver com Marie Noemi Alphonsine Lebrun, mais conhecida como Marinette, a residência do casal em São Paulo, na avenida Higienópolis, transforma-se em um importante centro de formação e de experimentação cultural dos setores de elite. ${ }^{20}$ Aos domingos, seus almoços tornam-se ponto de encontro de intelectuais, artistas plásticos e poetas, que lá encontram livros, revistas e obras recém-trazidas da Europa.

Na ausência de instituições culturais em São Paulo, Paulo Prado, ao lado de Olívia Guedes Penteado, destaca-se não apenas como anfitrião, mas também como promotor da arte moderna. Olívia, mesmo após a morte do marido, procura manter sua vida regrada pela etiqueta e pelos hábitos de luxo adquiridos em Paris e, a exemplo das damas da sociedade francesa, reserva, assim como Prado, um dia da semana, "le jour de Madame Penteado", para receber amigos, artistas e intelectuais em seu salão (Homem, 1996). Ao lado do palacete de Prado, o de Olívia, localizado à rua Conselheiro Nébias esquina com a Duque de Caxias, adquire um brilho excepcional no início do século XX.

Nos almoços dominicais oferecidos por Paulo Prado, assim como no "jour de Madame Penteado", os jovens modernistas encontram as últimas novidades da Europa, como livros, revistas e obras. Os acervos trazidos por eles da Europa continham uma mostra significativa dos artistas modernos da Escola de Paris, que terão grande impacto nos artistas ligados ao modernismo brasileiro: ilustrações e gravuras de André Derain (1880-1954), Gallanis (1880-1966) e Dunoyer de Segonzac (1884-1974); esculturas de Constantin Brancusi (1876-1957); pinturas de Pablo Picasso (1881-1973), Georges Braque (1882-1963), Juan Gris (1887-1927), Henri Matisse (1869-1954), Amedeo Modigliani (1884-1920), André Lhote (1885-1962), Léger, entre outros (Sevcenko, 1992).

Segundo Mário de Andrade, o salão de Paulo Prado era o mais seleto do período e o que teve duração mais longa (Andrade, M., 1974). Oswald de Andrade vai mais longe e afirma que foi durante esses almoços que se "elaborou" o modernismo: 
Paulo Prado abriu-nos sua casa em Higienópolis. Recebia magnificamente. Os seus almoços de domingo eram faustosos. Além de se comer e beber dentro de uma grande tradição civilizada, ali se debatiam os problemas candentes a transformação das letras e das artes. Pode-se dizer que, depois da pobreza de minha "garçonière" na Praça da República, foi a casa de Paulo Prado o centro ativo onde se elaborou o Modernismo (Andrade, O., 1954: 28).

Além de acatar a ideia de uma Semana de Arte Moderna, elaborada em sua residência, Paulo Prado teria feito a seguinte sugestão: "é preciso que seja uma coisa escandalosa, nada de festinha no gênero ginasial tão ao nosso gosto" (apud Thiollier, 1956: 115). Desse modo, com 53 anos na época, Prado figura ao lado de jovens intelectuais e artistas como personagem central do movimento que promove a Semana, no interior da qual, segundo suas próprias palavras, "com uma alegria iconoclasta e juvenil se quebram os antigos moldes e desaparecem as velhas regras, pesadas como grilhões" (Prado, P., 1924: 180).

O Teatro Municipal de São Paulo transforma-se assim no palco de um evento que se quer contestador, mas que conta com a presença de figuras oficiais, como o então governador Washington Luís (1869-1957). Pretendendo-se, nas palavras de Paulo Prado, um "ensaio ingênuo e ousado, de reação contra o Mau Gosto, a Chapa, o Já Visto, a Velharia, a Caduquice, o Mercantilismo", a Semana de Arte Moderna marcou uma data "memorável” no desenvolvimento literário e artístico do Brasil (Prado, 1924: 179).

Ao que parece, a ideia inicial de promover uma Semana de Arte Moderna partiu de Di Cavalcanti, que teria sugerido a Paulo Prado "uma semana de escândalos literários e artísticos, de meter os estribos na barriga da burguesiazinha paulistana" (Di Cavalcanti, 1955: 115). Marinette Prado, por outro lado, afirma ter sido dela a sugestão da realização de uma semana de manifestações similares às europeias (Amaral, 1998). Yan de Almeida Prado irá confirmar essa versão na dedicatória do livro A Grande Semana de Arte Moderna (1976): "A Marinette, que teve a ideia da Semana de Arte Moderna" (Prado, J. F., 1976). Aparentemente, no entanto, Di Cavalcanti é o responsável por levar a proposta adiante (Amaral, 1998). Polêmicas a parte, o fato é que o nome de Paulo Prado aparece sempre vinculado ao seu surgimento. ${ }^{21}$

Paulo Prado não somente simpatiza com a proposta, como lidera o comitê responsável pelas despesas, atraindo o patrocínio de figuras das altas elites paulistanas, a começar pelo irmão Antônio e pelo primo Martinho, ambos casados com mulheres da família Álvares Penteado, de onde também sairão contribuições financeiras. ${ }^{22}$ Com seu prestígio, explica Mário de Andrade, Paulo Pra- 
do "abr[iu] a lista das contribuições e arrast[ou] atrás de si os seus pares aristocratas e mais alguns que sua figura dominava" (Andrade, M., 1974: 237).

Não só seu nome é o primeiro a aparecer na lista dos financiadores da Semana de 1922, como é ele quem se encarrega do programa, da divulgação e dos demais detalhes para que o evento, no Teatro Municipal, tivesse um alcance retumbante(Sevcenko, 1992). Além disso, Prado ajuda financeiramente os participantes do evento, como o artista plástico Di Cavalcanti que, por ocasião da Semana, desabafa a Mário e Oswald de Andrade: "não é vergonha ser pobre e ser boêmio, digam logo a Paulo Prado que me falta dinheiro para pagar o hotel, e que ele compre uns desenhos meus, um quadro, o que ele quiser, para me sustentar aqui em São Paulo, por um mês" (Di Cavalcanti, 1955: 117). Prado teria se colocado à disposição do artista, tornando-se, segundo Di Cavalcanti, seu "amigo até morrer" (Ibidem).

Ainda que os artistas da primeira geração modernista fizessem parte do mesmo círculo de convivência, conhecendo-se e se fazendo reconhecer como integrantes das elites, faltava consistência ao mercado local das artes. O principal comprador era o poder público, que negociava suas aquisições politicamente, sem grandes compromissos, aten dendo os diversos lobbies comunitários e estilísticos de São Paulo (Sevcenko, 1992).

Nesse contexto, Paulo Prado adquire a imagem do colecionador de arte moderna, cuja coleção inclui não apenas pintores internacionais ligados às vanguardas, mas também artistas brasileiros modernos. Durante a controvertida exposição de Anita Malfatti, em 1917, por exemplo, Prado adquire o quadro "A Onda" (Batista et al., 2006). Pertencem também a ele os quadros "São Paulo" e "O Ovo", ambos de Tarsila do Amaral (Barata, 1969), além das esculturas "Cabeça de Mulher" - exposta durante a Semana de Arte Moderna -, "Safo", "Virgem" e "Ritmo", todas de Brecheret (Calil, 2004); e a tela "Sonho de uma Prostituta", de Cícero Dias (1907-2003), que Prado expõe no $1^{\circ}$ Salão de Maio (Ferraz, 1962). ${ }^{23}$

Assim, quando Paulo Prado efetua a única compra em uma exposição de Candido Portinari (1903-1962), o pintor doa-lhe outras duas obras como forma de agradecimento (Olinto, 1958). Mário de Andrade, em carta a Manuel Bandeira, explica a importância e repercussão dessas obras compradas por Prado: “ora, um quadro comprado pelo Paulo Prado significa não raro uns três ou quatro vendidos, de indivíduos que vão na onda dele, como Thiollier e de outros que criam coragem" (apud Moraes, 2000: 603). ${ }^{24}$

Lembremos que Paulo Prado teve também atuação decisiva em vários episódios que atuaram como prelúdios da Semana de 1922. A maioria dessas atividades públicas por ele organizadas e financiadas foi realizada no Teatro Municipal de São Paulo, cuja construção representa uma grande marca da administra- 
ção de seu pai como prefeito da cidade. São Paulo, dizia Antônio Prado, "não tinha vida social. Era necessário estimulá-la intensamente, por todos os meios e em todas as classes da população. Sem o que nunca passaria de um quieto burgo do interior" (apud Prado, N., 1929: 376).

O projeto do teatro paulistano foi encomendado a Cláudio Rossi (1850-1935), arquiteto da família Prado, que esteve na Europa para pesquisar e adquirir o material apropriado. Construído em terreno pertencente à Companhia Antártica Paulista, ligada empresarialmente a família Prado, que lhe fornecia os vasilhames da Vidraria Santa Marina, o Teatro Municipal de São Paulo tornou-se um reduto privilegiado de eventos de atualização da consciência artística e cultural, que tiveram lugar anos antes da famosa Semana de Arte Moderna (Bernardes, 2004).

As instalações do teatro paulistano contaram não apenas com a apresentação de óperas clássicas, mas também de bailados modernos como os de Isadora Duncan (1877-1927), em 1916, Vaslav Nijinski (1889-1950), em 1917 e 1918, e Anna Pavlovna (1881-1931), em 1918 e 1919. Além disso, a Orquestra Sinfônica Italiana, sob a regência do maestro Gino Marinnuzzi (1882-1945), reunirá em um mesmo programa, em 1919, Debussy (1862-1918), Respighi (1879-1936) e Wagner (1813-1883). Essa sequência terá prosseguimento com Arthur Rubinstein (1887-1982), em 1920 e 1922, executando ao piano Stravinsky (1882-1971), Debussy e Villa Lobos, entre outros, e também com a pianista Luba d'Alexandrowska, apresentando Ravel (1875-1937) e Debussy, em 1921 (Sevcenko, 1992).

Paralelamente às iniciativas nas áreas musical, cenográfica e coreográfica, Paulo Prado, em colaboração com o senador Freitas Valle (1870-1958) e com o dramaturgo e poeta francês Paul Claudel (1868-1955) - com quem ele já havia negociado o Convênio Franco-Brasileiro ${ }^{25}$-, instala no Teatro Municipal de São Paulo, em 1919, a Exposição de Pinturas e Esculturas Francesas. A parte de pintura, segundo Sevcenko (1992), é fraca, mas a de escultura é representada por Antoine Bourdelle (1861-1929), Auguste Rodin (1840-1917) e Henri Laurens (1885-1954).

Tal exposição irá coroar um momento exemplar de modernização da consciência cultural e artística brasileira, pois ainda que a Pinacoteca do Estado, primeiro museu da cidade, inaugurado em 1905, já possuísse um acervo de pinturas e esculturas, ele estava mais voltado para a arte brasileira do século XIX (Araujo e Camargos, 2007). É importante ressaltar que se a presença do presidente do estado de São Paulo, do prefeito e respectivos altos escalões nessas exposições era frequente, quem efetivamente patrocinava os artistas locais era "um apanágio de patronos abastados" (Sevcenko, 1992: 235), como é o caso de Paulo Prado. 
Além de abrigar exposições e espetáculos estrangeiros, que reforçariam a imagem da cidade progressista à europeia, o Teatro Municipal de São Paulo, no final da década de 1910, abre espaço para a monumental montagem dramático-musical $O$ Contratador de Diamantes, baseada na obra póstuma de Afonso Arinos. Contemporâneo de Paulo Prado no Largo São Francisco, Arinos posteriormente tornou-se seu cunhado, ao casar-se com Antonieta Prado; recebeu também de Eduardo Prado a direção do jornal monarquista O Comércio de São Paulo, em 1897, e o substituiu na cadeira número 40 da Academia Brasileira de Letras. Desse modo, a encenação não só traz para a ordem do dia o nome de Arinos, como também - e principalmente -, revelará um novo cenário cultural que se desenhava com a ajuda fundamental da família Prado.

A peça envolve os Prados e as principais famílias da elite paulista como patronos e mesmo como atores de uma representação ficcional da saga dos bandeirantes. No lugar de profissionais, atuam na peça os próprios membros das elites paulistanas, entre os quais Antonieta Penteado Prado, irmã de Paulo; Eglantina Penteado Prado, sua cunhada; e o futuro historiador Caio Prado Júnior, seu sobrinho, ainda com 15 anos, representando no espetáculo seus supostos antepassados, fundadores da pátria (Sevcenko, 1992; Iumatti, 2007). É curioso notar que todo o luxuoso mobiliário e a prataria de época utilizados na peça são parte do próprio patrimônio das famílias Prado e Penteado (Sevcenko, 1992).

Sucesso de público e de crítica, a peça ganha destaque, em tom de escândalo, devido à apresentação da congada com dançarinos "pretos de verdade", ao lado de violeiros "autênticos da roça", como os definiu o jornal $O$ Estado de S. Paulo (Sevcenko, 1992: 242). Assim, o palco do Teatro Municipal de São Paulo, em 1919, já inicia, com a ajuda dos Prados, uma valorização do "popular", do "folclórico" e do "colonial", elementos chaves do programa modernista posterior.

No bojo dessa grande efervescência no campo das idéias, tem lugar a célebre Semana de Arte Moderna, em fevereiro de 1922. A imagem desse evento como um marco na renovação cultural do país (Brito, 1997; Amaral, 1998; Martins, 2003) tem sido, já há alguns anos, criticada por estudos que procuram atenuar seu caráter de ruptura (Igreja, 1989; Hardman, 1992; Chiarelli, 1995; Miceli, 2003). No entanto, embora muitos autores já tenham se debruçado sobre o tema, interrogando criticamente o significado do modernismo de São Paulo para a história da literatura brasileira, o fato é que a Semana agitou o ambiente paulistano.

Cândido Motta Filho relembra um diálogo no qual o poeta Ronald de Carvalho comenta que a "reunião modernista" estava "cheia de passadistas", ao que Paulo Prado teria respondido: "isso não tem importância. O importante é a reunião!” (Motta Filho, 1962). O primordial era desafiar um gosto consolidado 
com algo diferente daquilo que a Academia ensinava, ou, ao menos, tentar fazê-lo. Nesse sentido, se a intenção deliberada do evento era chocar, de fato, a platéia saiu de lá, no mínimo, incomodada, como demonstram as vaias e gritos de desaprovação. Inclusive, conta Geraldo Ferraz, era Paulo Prado quem gritava, ao calor das vaias do público, sugestões para dominar o alvoroço e prosseguir sem problemas com o evento (apud Eulalio, 1993).

Ainda que não tenha produzido nada de substancial ou representativo por ocasião da Semana de Arte Moderna, e que sua obra seja realizada no campo do ensaio, e não no da literatura ou no das artes plásticas, que constituem o núcleo do movimento, Paulo Prado é reiteradamente aclamado como quem deu expressão e visibilidade ao evento. Ninguém melhor que ele, portanto, para ser o verdadeiro "fautor" da Semana de Arte Moderna, como indica Mário de Andrade em um balanço do evento, 20 anos depois:

(...) alguém lançou a ideia de se fazer uma semana da arte moderna, com exposição de artes plásticas, concertos, leituras de livros e conferências explicativas. Foi o próprio Graça Aranha? Foi Di Cavalcanti? Porém, o que importa era poder realizar essa ideia, além de audaciosa, dispendiosíssima. E o fautor verdadeiro da Semana de Arte Moderna foi Paulo Prado. E só mesmo uma figura como ele e uma cidade grande, mas provinciana como São Paulo, poderiam fazer o movimento modernista e objetivá-lo na Semana (Andrade, M., 1974: 234-235).

Tudo isso rende a Paulo Prado a imagem do grande "promotor" do evento, que irá também atuar como um mediador entre os jovens do grupo e Graça Aranha. Oswald de Andrade, também em um balanço posterior da Semana, ressalta a importância de Prado para a sociabilidade intelectual do "grupo":

Ele colocava em sua frente Graça Aranha, geralmente confuso e parlapatão, filho duma abominável formação filosofante do século XIX, mas grande homem nacional, pertencente a nossa Academia de Letras, e autor de um livro tabu "Canaan" que ninguém havia lido e todos admiravam. Era evidente que para nós, sobretudo o apoio oficial de Graça Aranha representava um presente do céu. Com seu endosso, seríamos tomados a sério. Do contrário, era difícil. Sem a inteligência e a compreensão de Paulo Prado, nada teria sido possível. Ele foi o agente de ligação entre o grupo que se formava e o medalhão Graça Aranha (Andrade, O., 1954: 28). 
Diante desse quadro, Paulo Prado pode ser considerado como um elo entre diferentes tendências, seja entre o "grupo que se formava" e o "medalhão Graça Aranha", ou mesmo dentro do próprio "grupo que se formava". Vemos, então, que a relação de Prado com o "grupo" que promove a Semana de 1922 tomou também o campo das relações pessoais. Vale lembrar que Prado é padrinho por parte da noiva, ao lado de Olívia Guedes Penteado, do casamento de Oswald e Tarsila, em 1926. Temos aí constituída "uma parceria de afinidades que sinalizam o lastro social no qual se entranhava o entrosamento ideal perseguido pelos modernistas, entre cultura, política e mundanismo" (Miceli, 2003: 143).

Como desdobramento da Semana de Arte Moderna, são lançadas diversas revistas de divulgação da produção modernista e o nome de Paulo Prado aparece muitas vezes associado à fundação e ao controle de boa parte dessas publicações. Após integrar o grupo da Klaxon, ele assume, entre 1923 e 1925, o controle da Revista do Brasil, uma das publicações brasileiras de maior repercussão e longevidade no início do século XX. ${ }^{26}$ Idealizada em 1915 por Júlio de Mesquita (1962-1927), jornalista e também proprietário do jornal O Estado de S. Paulo, a Revista do Brasil é controlada de 1918 a 1925 pelo escritor Monteiro Lobato (1882-1948). Devido ao sucesso da publicação, Lobato e seu sócio, Marcondes Octalles Ferreira, fundam a editora Monteiro Lobato \& Cia. - que conta com a colaboração financeira de Prado na montagem do parque gráfico - e, como é sabido, revolucionam o mercado editorial brasileiro (De Luca, 1999).

Ao se tornar importante personagem em um mercado editorial ainda acanhado, Paulo Prado ganha prestígio, mas também inimizades. Manuel Bandeira, por exemplo, ao descobrir que Lobato não editará mais seus versos, critica Paulo Prado: "há na empresa de Lobato capitais de Paulo Prado. Eles devem sair! Ou então o Paulo Prado saia do meio de nós!” (apud Moraes, 2000: 118). Lobato também não publica Paulicéia desvairada (1922), de Mário de Andrade, e Bandeira desabafa mais uma vez:

Paulo Prado faz a semana de arte moderna, aceita almoço dos klaxistas e, rico, deixa morrer a Klaxon, e sócio da casa editora de Vasco Porcalho \& Cia [Monteiro Lobato], permite que eu e Mário de Andrade sejamos escorraçados pela firma em favor de parnasianos e caboclistas (Bandeira, 1986: 248).

Apesar das críticas, Paulo Prado não deixa de auxiliar financeiramente a manutenção da Revista do Brasil, como queria Manuel Bandeira, mas tampouco se afasta dos círculos modernistas. Junto a Antônio de Alcântara Machado (1901-1935), Couto de Barros (1896-196)e Sérgio Milliet - assim como ele, ex-in- 
tegrantes do grupo da Klaxon -, funda e financia a segunda revista modernista de São Paulo, a Terra Roxa e outras terras, ${ }^{27} \mathrm{em}$ janeiro de 1926.

Alguns anos depois, em 1931, Paulo Prado novamente se associa a Alcântara Machado e Mário de Andrade. Juntos, fundam a Revista Nova, também divulgadora das ideias modernistas. No entanto, a publicação dura pouco mais de um ano, devido a "muita literatura gratuita" e pouco financiamento. Mário de Andrade esclarece um pouco a situação:

Está claro que se a gente pedisse tenho certeza que Paulo Prado sustentaria a revista com o dinheiro dele, mas isso não nos conviria, você compreende, porque nos deixava ao Alcântara e a mim, numa situação indiscutível de subalternidade que não seria envergonhante eu sei, mas era sempre dessagradável, quanto à orientação da revista (apud Fernandes, 1968: 96). ${ }^{28}$

Ainda que essencial, a ajuda do mecenas é sempre vista com desconfiança, pois implica concessões e negociações, já que o mecenato, ao mesmo tempo em que garante subsídios, constrói novas hierarquias. Não à toa que Mário de Andrade faz questão de deixar claro que não quer contaminar a relação de amizade que cultiva com Prado através de assuntos econômicos - ainda que estes façam parte, efetivamente, de suas relações -, e conclui: "sou muito amigo dele [Paulo Prado], muito, mas é mais fácil a ele ser meu amigo do que a mim ser amigo dele" (apud Moraes, 2000: 585). ${ }^{29}$ Já Alcântara Machado - que, por ocasião da fundação de Terra Roxa e outras terras, havia comentado que o fato de Prado ser um dos "capitalistas da empresa" era "[um] segredo! Ou como se fosse"-, ao fundar a Revista Nova prefere abrir mão da ajuda financeira de Prado, ainda que ele seja seu sócio (apud Lara, 1972, 11-12). ${ }^{30}$

Poucos antes da fundação da Revista Nova, em meio aos debates acerca da publicação de Retrato do Brasil, Paulo Prado também rompe a amizade com Oswald de Andrade, pois lhe atribui a autoria de "Moquém/ I- Aperitivo", resenha publicada em 1929 na Revista de Antropofagia, sob o pseudônimo de Tamandaré. Nesse texto, o segundo livro de Prado é descrito como uma obra ruim, repleta de injustiças e inverdades. Prado, de rapaz interessante, torna-se "um espírito à margem do século, cândido, ingênuo, piedoso, incapaz de devorar com prazer e a goles de cauim uma canela do próximo" (Tamandaré, 1929).

É provável que a resenha tenha sido publicada por se acreditar que Paulo Prado estivesse na Europa no período, mas devido a uma enfermidade do pai, ele permanece no país e toma conhecimento da crítica (Amaral, 2001). Oswald de Andrade tenta eximir-se da responsabilidade pelo texto, mas Prado não atende 
aos seus telefonemas, rompendo de vez a amizade entre os dois (Boaventura, 1995). Geraldo Ferraz, responsável pela direção da segunda fase do periódico, explica, posteriormente, que Tamandaré é o pseudônimo de outro colaborador da Revista de Antropofagia, Oswaldo Costa (Ferraz, 1985).

Lembremos que Oswald de Andrade - que, em 1924, havia dedicado a Paulo Prado seu livro Memórias Sentimentais de foão Miramar - em artigo publicado também por ocasião do lançamento de Retrato do Brasil, em O Fornal, descreve Prado como o "melhor escritor brasileiro vivo" de sua geração (Andrade, O., 1929). Ainda assim, o movimento antropofágico e a Revista de Antropofagia estavam diretamente relacionados a ele e Prado não perdoa a publicação do comentário crítico ao seu livro.

Falar em "grupo modernista" no singular, portanto, faz-nos correr o risco de perder de vista a sua pluralidade, o que permite perceber o quão larga pode ser a definição do modernismo brasileiro. A própria Semana de Arte Moderna basta ver a programação e o comitê organizador - revela, de saída, a heterogeneidade do grupo. O presente artigo mostra como a presença de Paulo Prado e Graça Aranha no certame é um claro exemplo da heterogeneidade geracional, estética e ideológica que cercava o "grupo". Há um conflito de gerações, de posições e de postos, de modo que os pensadores e as correntes que se reúnem em torno da Semana de Arte Moderna logo se separam, dando uma mostra do complexo painel da vida intelectual brasileira.

Notas

1. Além de artigos, resenhas e capítulos em livros e verbetes, o que existe em termos de trabalho sistemático sobre Paulo Prado é o livro de Carlos Eduardo Ornelas Berriel (2000). Já sobre Graça Aranha, há a biografia escrita por Maria Helena Azevedo (2002).

2. Para um balanço posterior do movimento modernista de 1922 feito pelos seus próprios participantes, Oswald de Andrade (1954), Di Cavalcanti (1955), Mário de Andrade (1974), entre outros.

3. Carta de Antônio Prado a Graça Aranha, fevereiro de 1915.
4. Carta de Graça Aranha a Antônio Prado, fevereiro de 1915.

5. Entre 1911 e 1924, Paulo Prado alternou os cargos de diretor-gerente e diretorpresidente da Companhia Prado Chaves, mantendo, a partir de 1924, a presidência da empresa.

6. Carta de Graça Aranha a Maria Genoveva de Araújo, s/d.

7. Carta de Graça Aranha a Maria Genoveva de Araújo, 20 de janeiro de 1922.

8. No chamado "primeiro tempo modernista", iniciado, grosso modo, em 1917, o 
que se pretendia, em linhas gerais, era o ingresso do Brasil na modernidade, por meio de um esforço em contrapor-se ao passadismo, entendido como inatual, e de uma tentativa de adoção da linguagem das vanguardas européias, que seriam mais adequadas ao tempo e à vida presentes. $\mathrm{A}$ partir de 1924, no entanto, é possível identificar um "segundo tempo modernista", no qual aparece de forma mais explicita a ideia de que a inserção do país no mundo contemporâneo deveria ser buscada através da singularidade brasileira. Ser moderno passa a ser sinônimo não só de ser civilizado, cosmopolita e atualizado com o mundo, mas também de ser brasileiro (Jardim,1978).

9. Sobre as repercussões de $A$ estética $d a$ vida na proposta dos modernistas, ver Eduardo Jardim (1978) e Antônio Arnoni Prado (1983).

10. Sobre a revista Klaxon, ver Cecília de Lara (1972).

11. Carta de Mário de Andrade a Manuel Bandeira, 10 de outubro de 1924.

12. A partir do chamado "segundo tempo modernista", quando o Brasil procura ingressar no concerto internacional das nações por intermédio daquilo que é nacional (Jardim, 1978), diferentes são as soluções propostas para a realização dessa tarefa. É possível destacar, pelo menos, três soluções bem definidas. A primeira pretendia "dispensar o todo", como é o caso do Movimento Verde-Amarelo (1926), que se desdobraria no grupo Anta (1927). Seus maiores expoentes são Cassiano Ricardo, Menotti Del Picchia e Plínio Salgado, que defendiam o abandono das influências europeias, fixando-se na originalidade brasileira e em seus mitos fundadores. Já a segunda, ambicionava "deglutir o todo" pelo "canibalismo cultural" e adaptá-lo às condições específicas do Brasil, conforme propõe Oswald de Andrade em seu Manifesto Antropófago (1928). A terceira, por fim, aspirava "incorporar-se ao todo". A "via analítica" de Mário de Andrade, autor que se dedica aos estudos da música e da cultura popular, é a maior representante deste grupo, que mais tarde criará o Serviço do Patrimônio Histórico (Oliveira, 1998: 191).

13. Carta de Mário de Andrade a Manuel Bandeira, 22 de novembro de 1924.

14. Carta de Mário de Andrade a Paulo Prado, 1925.

15. Sobre a revista Movimento Brasileiro, ver Maria Eugênia Boaventura (1978).

16. Carta de Mário de Andrade a Paulo Prado, 1925.

17. Entrevista concedida por Oswald de Andrade a Arruda Dantas, em janeiro de 1950.

18. Nascido Frédéric Louis Sauser.

19. Nascido Charles-Édouard Jeanneret.

20. A residência do casal, no número 31 da avenida Higienópolis, é posteriormente renumerada como 617 e demolida no início de 1975 (Eulálio e Calil, 2001).

21. Sobre o nascimento da ideia da Semana de 1922, ver Oswald de Andrade (1954), Manuel Bandeira (1954), Di Cavalcanti (1955), René Thiollier (1956), Mário de Andrade (1974), J. F. de Almeida Prado (1976), entre outros.

22. O Correio Paulistano, em 29 de janeiro de 1922, anuncia o preparo da "semana da arte" e informa que "a comissão que patrocina esta iniciativa está assim organizada: Paulo Prado, Alfredo Pujol, Oscar Rodrigues Alves, Numa de Oliveira, Alberto Penteado, René Thiollier, Antônio Prado Junior, José Carlos Macedo Soares, Martinho Prado, Armando Penteado e Edgar Conceição".

23. Idealizado e batizado por Quirino da Silva, o Salão de Maio teve três edições na cidade de São Paulo, entre 1937 e 1939. Seu 
objetivo era criar um espaço para a arte moderna nacional, assim como promover o intercâmbio com a produção internacional, o que ocorreu, sobretudo, a partir do $2^{\circ}$ Salão, em 1938. Por ocasião do $1^{\circ}$ Salão, Prado aconselhou Ferraz a intitular o quadro "Sonho de uma Prostituta" como "Composição $n^{\circ} 1$ ", evitando assim possíveis escândalos (Ferraz, 1962).

24. Carta de Mário de Andrade a Manuel Bandeira, 16 de dezembro de 1934.

25. Em 1917, Paulo Prado havia negociado o Convênio Franco-Brasileiro com Paul Claudel, então encarregado dos negócios da França no Brasil. Como resultado dessa negociação, ficou determinada uma aproximação do Brasil com os Aliados na Primeira Grande Guerra e a transferência

\section{Referências bibliográficas}

AMARAL, Aracy. Artes plásticas na Semana de 22. $5^{\text {a }}$ ed. São Paulo: Editora 34, 1998.

(org.). Correspondência Mário de Andrade E Tarsila do Amaral. São Paulo: Edusp/ IEB, 2001.

Tarsila, sua obra e seu tempo. $3^{\mathrm{a}}$ ed. São Paulo: Editora 34/Edusp, 2002.

ANDRADE, Mário de. Carta Aberta a Alberto de Oliveira. In: Estética. Rio de Janeiro, n.3. 1925.

O Movimento Modernista. In: Aspectos da literatura brasileira. $5^{\mathrm{a}}$ ed. São Paulo: Martins, 1974.

ANDRADE, Oswald de. Poesia Pau Brasil. Paris: Au Sans Pareil, 1925.

Retoques ao Retrato do Brasil. $O$ fornal, 6 de janeiro de 1929. para a França dos navios alemães apreendidos nas costas brasileiras, em troca da compra de dois milhões de sacas de café operação que seria intermediada pela Companhia Prado Chaves.

26. Sobre a Revista do Brasil, de sua fundação até 1925, ver Tânia de Luca (1999).

27. Sobre Terra Roxa e outras terras, ver Cecília de Lara (1972).

28. Carta de Mário de Andrade a Augusto Meyer, 28 de fevereiro de 1932.

29. Carta de Mário de Andrade a Manuel Bandeira, 4 de setembro de 1934.

30. Carta de Alcântara Machado para Prudente de Morais Neto, 31 de dezembro de 1925.
- O Modernismo. Anhembi. São Paulo, v. XVII, n. 49, ano X, 1954.

ANJOS, Cyro dos. Graça Aranha, sua vida, sua obra. Revista de Letras. Assis, v. 17. 1975.

ARANHA, Graça. Obra completa. Rio de Janeiro: MEC/INL, 1968.

ARAUJO, Marcelo \& CAMARGOS, Márcia. Pinacoteca do Estado: a história de um museu. São Paulo: Pinacoteca, 2007.

AZEVEDO, Maria Helena. Um senhor modernista: biografia de Graça Aranha. Rio de Janeiro: Academia Brasileira de Letras, 2002.

BANDEIRA, Manuel. Apresentação da poesia brasileira. $2^{\mathrm{a}}$ ed. Rio de Janeiro: Casa do Estudante, 1954. 
BARATA, Mário. Sua presença na cultura brasileira. O Estado de S. Paulo. Suplemento Literário, 15 de junho de 1969.

BARBOSA, Francisco. A vida de Lima Barreto. Rio de Janeiro: José Olympio, 1952.

BATISTA, Marta Rosetti; LIMA, Yone de \& LOPEZ, Telê. Brasil: $1^{\circ}$ tempo modernista 1917-1929. São Paulo: IEB, 1972.

BERNARDES, Maria Elena. $O$ estandarte glorioso da cidade: Teatro Municipal de São Paulo (1911-1938). Tese (Doutorado em História) - Universidade de Campinas, 2004.

BERRIEL, Carlos. Tietê, Tejo e Sena: a obra de Paulo Prado. Campinas: Papirus, 2002.

BOAVENTURA, Maria Eugênia. Movimento Brasileiro: contribuição ao estudo do modernismo. São Paulo: Comissão Estadual de Artes e Ciências Humanas, 1978.

. OSalão e a Selva: uma biografia ilustrada de Oswald de Andrade. São Paulo: Ex Libris; Campinas: Unicamp, 1995.

(org.). 22 por 22: a Semana de Arte Moderna vista pelos seus contemporâneos. São Paulo: EDUSP, 2000.

BRITO, Mário. História do modernismo brasileiro: antecedentes da semana de arte moderna. $6^{\mathrm{a}}$ ed. Rio de Janeiro: Civilização Brasileira,1997.

CALIL, Carlos Augusto (org.). Retrato do Brasil: ensaio sobre a tristeza brasileira. $9^{\mathrm{a}} \mathrm{ed}$. São Paulo: Companhia das Letras, 1997.

- (org.). Paulística etc. $4^{\mathrm{a}}$ ed. São Paulo: Companhia das Letras, 2004.

CENDRARS, Blaise. Trop C'est Trop. Paris: Denoël, 1957.

CHIARELLI, Tadeu. Um jeca nos vernissages. São Paulo: Edusp, 1995.

DANTAS, Antônio. Dona Olívia. São Paulo: Sociedade Impressora Pannartz, 1975.
DI CAVALCANTI, Emiliano. Viagem $d a$ minha vida $-1^{\circ}$ testamento da alvorada. Rio de Janeiro: Civilização Brasileira, 1955.

EULALIO, Alexandre. Paulo Prado: Retrato do Brasil. In: Livro involuntário: literatura, história, matéria e memória. Rio de Janeiro: UFRJ, 1993.

$\&$ CALIL, Carlos Augusto (org.). $A$ aventura brasileira de Blaise Cendrars. São Paulo: Edusp, 2001.

HARDMAN, Francisco. Antigos Modernistas. In: NOVAES, Adauto (org.). Tempoe história. São Paulo: Companhia das Letras/Secretaria Municipal de Cultura, 1992.

FERNANDES, Lygia. Mário de Andrade escreve cartas a Alceu, Meyer e outros. Rio de Janeiro: Editora do Autor, 1968.

FERRAZ, Geraldo. Perfil de um homem e de um livro. In: Retrato do Brasil: ensaio sobre a tristeza brasileira. $6^{\mathrm{a}}$ ed. Rio de Janeiro: José Olympio, 1962.

. Entrevista com Geraldo Ferraz. In: BOAVENTURA, Maria Eugênia. $A$ vanguarda antropofágica. São Paulo: Ática, 1985.

HOMEM, Maria Cecília. O Palacete Paulistano. São Paulo: Martins Fontes, 1996.

IGREJA, Francisco. A Semana Regionalista de 1922. São Paulo: Edicon, 1989.

IUMATTI, Paulo. Caio Prado Fr.: uma trajetória intelectual. São Paulo: Brasiliense, 2007.

JARDIM, Eduardo. A brasilidade modernista: sua dimensão filosófica. Rio de Janeiro: Graal, 1978.

LARA, Cecília de. Klaxon E Terra Roxa e outras terras: dois periódicos modernistas de São Paulo. São Paulo: IEB/USP, 1972.

MARTINS, Wilson. A literatura brasileira: $o$ modernismo (1916-1945). $2^{\text {a }}$ ed. São Paulo: Cultrix, 1965. 
MICELI, Sérgio. Nacional e estrangeiro. São Paulo: Companhia das Letras, 2003.

MORAES, Marco Antônio de (org.). Correspondência Mário de Andrade E Manuel Bandeira. São Paulo: Edusp/IEB, 2000.

MOTTA FILHO, Cândido. Novos depoimentos sobre a Semana de Arte Moderna. O Estado de S. Paulo. São Paulo, 14 abril de 1962.

OLINTO, Décio. Paulo Prado, o lavrador. Correio da Manhã, 11 outubro de 1958.

OLIVEIRA, Lúcia Lippi. Questão nacional na Primeira República. In: DE LORENZO, Helena Carvalho \& COSTA, Wilma Peres (orgs.). A década de 1920 e as origens do Brasil moderno. São Paulo: Unesp, 1998.

PRADO, Antônio Arnoni. 1922 - Itinerários de uma falsa vanguarda. Os dissidentes, a Semana, o integralismo. São Paulo: Brasiliense, 1983.

PRADO, João Fernando de Almeida. $A$ Grande Semana de Arte Moderna: depoimento e subsídios para a cultura brasileira. São Paulo: EDART, 1976.

PRADO, Nazareth. Antônio Prado no Império e na República. Rio de Janeiro: F. Briquet \& Cia., 1929

PRADO, Paulo. Prefácio. In: COELHO, Henrique. Foaquim Nabuco - esboço biográfico. São Paulo: Monteiro Lobato, 1922.

\author{
- Brecheret. Revista do Brasil. São \\ Paulo, v. 25, n. 98, 1924.
}

- Paulística: história de São Paulo. São Paulo: Monteiro Lobato, 1925.
- Prefácio. In: ANDRADE, Oswald. Poesia Pau Brasil. Paris: Au Sans Pareil, 1925.
- Uma hora com o Sr. Paulo Prado. $O$ Fornal, 25 de dezembro de 1926.
- Retrato do Brasil: ensaio sobre a triste- za brasileira. São Paulo: Duprat-Mayença, 1928.

SEVCENKO, Nicolau. Orfeu estático na metrópole: São Paulo, sociedade e cultura nos frementes anos 20. São Paulo: Companhia das Letras, 1992.

SILVA, Hélio. 1922, Sangue na Areia de Copacabana. $2^{\mathrm{a}}$ ed. Rio de Janeiro: Civilização Brasileira, 1964.

SOUSA, Pedro Luís. L. Meus cinquenta anos na Companhia Prado Chaves. São Paulo: Revista dos Tribunais, 1950.

TAMANDARÉ. Moquém/ I - Aperitivo. Revista de Antropofagia, n. 4, 7 de abril de 1929.

THIOLLIER, René. A Semana de Arte Moderna (depoimento inédito de 1922). São Paulo: Cupulo, 1953

\section{Resumo}

Reconhecidos como personagens centrais pelo grupo de intelectuais e artistas ligados à Semana de Arte Moderna de 1922, Graça Aranha e Paulo Prado são muitas vezes deixados de lado pelos estudiosos e, em geral, se fazem presentes nas análises de bastidores e/ou em referências de terceiros. Este artigo pretende observar mais atentamente suas redes de sociabilidade e inserção, o que revela, entre outras coisas, as ambivalências do engate de ambos os 
autores em um projeto "moderno", assim como certas ambivalências presentes no interior do próprio movimento modernista.

Palavras-chave: Paulo Prado, Graça Aranha, Semana de Arte moderna, Modernismo.

\begin{abstract}
Well-recognized key characters among intellectuals and artists involved in the 1922 Week of Modern Art, Graça Aranha and Paulo Prado are quite often disregarded by scholars and acknowledged as backstage personalities with a supporting role. The objective of this article is to analyze more carefully their social network and insertion, revealing, among other things, the ambivalences of their "modern" project, as well as the ambivalences of the modernist movement itself.

Key words: Paulo Prado, Graça Aranha, 1922 Week of Modern Art, Modernism.
\end{abstract}

\title{
Résumé
}

Reconnus comme personnages centraux par le groupe d'intellectuels et d'artistes de la Semaine d'Art Moderne de 1922, Graça Aranha et Paulo Prado sont souvent oubliés par les académiciens et les critiques, en général, sont représentés en coulisses et/ou en réference à des tiers. Cet article propose d'examiner de plus près leurs réseaux de sociabilité et d'intégration, qui montre, entre autres choses, l'ambivalence de l'articulation des deux auteurs sur un projet "moderne", ainsi que certaines ambiguittés présentes au sein du propre mouvement moderniste.

Mots-clés: Paulo Prado, Graça Aranha, Semaine d'Art Moderne, Modernisme 